\title{
Produtos naturais para o controle do ácaro Varroa destructor em abelhas africanizadas
}

\author{
Guido Laércio Bragança Castagnino(1) e Ricardo de Oliveira Orsi ${ }^{(2)}$
}

\begin{abstract}
(1)Universidade Federal da Bahia, Departamento de Produção Animal, Avenida Ademar de Barros, no 500, CEP $40170-110$ Salvador, BA. E-mail: gbcastagnino@yahoo.com.br(2)Universidade Estadual Paulista, Faculdade de Medicina Veterinária e Zootecnia de Botucatu, Departamento de Produção Animal, Fazenda Experimental Lageado, CEP 18618-000 Botucatu, SP. E-mail: orsi@fmvz.unesp.br
\end{abstract}

Resumo - O objetivo deste trabalho foi avaliar os efeitos do ácido oxálico e de óleos essenciais de plantas no controle da infestação pelo ácaro Varroa destructor em colônias de Apis mellifera africanizadas. O experimento foi realizado em delineamento inteiramente casualizado, em 30 colônias, com seis tratamentos e cinco repetições. As colmeias foram tratadas com óleos essenciais de arruda (Ruta graveolens), eucalipto (Eucalyptus spp.) e hortelã (Mentha piperita), além de timol, ácido oxálico e do tratamento controle sem aplicação de produtos. Foram avaliadas a mortalidade de varroas e as taxas de mortalidade de crias e de infestação de varroas em crias e em abelhas adultas, antes e depois da aplicação de cada produto. O ácido oxálico e os óleos de arruda, timol, eucalipto e de hortelã reduziram a mortalidade de crias parasitadas pelo ácaro em 92,1, 83,3, 81,7, 86,4 e $81,3 \%$, respectivamente. O tratamento com ácido oxálico reduziu em $87,4 \%$ a infestação de varroas em abelhas adultas. $\mathrm{O}$ uso desses produtos é eficiente na redução da mortalidade de crias de $A$. mellifera parasitadas por V. destructor.

Termos para indexação: Apis mellifera, ácaro, ácido oxálico, óleos essenciais.

\section{Natural products for the control of the mite Varroa destructor in Africanized bees}

\begin{abstract}
The objective of this work was to evaluate the effects of oxalic acid and essential oils of plants on the control of Varroa destructor infestation in Africanized Apis mellifera colonies. The experiment was carried out in a completely randomized design, in 30 colonies, with six treatments and five replicates. Beehives were treated with essential oils of common rue (Ruta graveolens), eucalyptus (Eucalyptus spp.), and mint (Mentha piperita), besides thymol, oxalic acid, and a control treatment without product application. Varroa mite mortality levels, bee offspring mortality rate, and the varroa mite infestation rate in offspring and adult bees were evaluated before and after the application of each product. Oxalic acid and oils of common rue, thymol, eucalyptus and mint reduced significantly the mortality of offspring parasitized by this mite in 92.1 , $83.3,81.7,86.4$, and $81.3 \%$, respectively. The treatment with oxalic acid also reduced varroa mite infestation in adult bees in $87.4 \%$. The use of these products is efficient in reducing the mortality of $A$. mellifera offspring parasitized by $V$. destructor .
\end{abstract}

Index terms: Apis mellifera, mite, oxalic acid, essential oils.

\section{Introdução}

O ácaro ectoparasita Varroa destructor é atualmente uma das pragas apícolas de maior interesse mundial. Classificado inicialmente como Varroa jacobsoni Oud., foi descrito pela primeira vez em 1904 e renomeado posteriormente como $V$. destructor (Anderson \& Trueman, 2000). O ácaro, que afeta tanto crias como abelhas adultas, tornou-se parasita da Apis mellifera $\mathrm{L}$. a partir da década de 1970. Atualmente, está presente em várias regiões do mundo (Tentcheva et al., 2006).

No Brasil, essa praga foi introduzida em 1972, dispersou-se rapidamente e, hoje, é encontrada em todo o país. Nos últimos anos, as taxas de infestação aumentaram e, em algumas regiões brasileiras, já se assemelham às observadas na Europa (Carneiro et al., 2007). Os danos causados pelos ácaros dependem do nível de infestação da colônia; entre os principais sintomas estão a má-formação de diversos órgãos e a redução do peso de zangões e operárias, o que compromete a longevidade da população da colônia (Duay et al., 2003).

Para minimizar os efeitos da infestação de varroa, vários acaricidas sintéticos foram desenvolvidos, como os organofosforados e piretroides. Entretanto, 
nos últimos anos, o uso contínuo desses produtos tem acarretado altos níveis de resistência às populações de ácaros (Lodesani, 2004), além da possibilidade de esses produtos contaminarem o mel e a cera no interior da colônia (Bogdanov, 2006).

Tal situação tem incentivado estratégias para minimizar a resistência e o acúmulo desses resíduos químicos na cera e no mel. Assim, é crescente o interesse de pesquisadores e apicultores por alternativas de combate às doenças e pragas, entre as quais está o controle de varroa por meio de produtos naturais.

Os óleos essenciais servem a várias funções nas plantas, entre elas a de defendê-las contra o ataque de insetos, ácaros e patógenos, ao exercer efeito tóxico nesses organismos. Baggio et al. (2004) constataram que muitos desses óleos mostraram atividade acaricida no controle do endoparasita Acarapis woodi. Segundo Damiani et al. (2009), esses produtos são eficazes no controle do $V$. destructor e podem ser utilizados na redução dessa praga.

O timol, composto farmacologicamente ativo, é extraído do óleo essencial do tomilho (Thymus vulgaris), planta aromática utilizada na culinária mediterrânea. Sua eficiência acaricida já foi comprovada por Stanghellini \& Raybold (2004) e May-Itzá et al. (2007). Outra substância natural que vem sendo testada é o ácido oxálico. Pesquisas mostram que este produto é altamente eficaz no controle da varroa, quando a colônia possui pouca ou nenhuma cria operculada (Gregorc \& Planinc, 2002). Várias formas de aplicação com diferentes concentrações de ácido oxálico, já foram testadas, tendo-se obtido diferentes índices de mortalidade de varroa. Em experimento com solução composta de $2,9 \%$ de ácido oxálico, em $31,9 \%$ de açúcar diluído em água, Gregorc \& Poklukar (2003) observaram mortalidade superior a 97\%. Toomemaa et al. (2010), ao aplicar solução de $0,5 \%$ de ácido oxálico em colônias com pouca cria operculada, obtiveram $92 \%$ de eficácia sem apresentar toxicidade para as abelhas.

O objetivo deste trabalho foi avaliar os efeitos do ácido oxálico, do timol e de óleos essenciais de arruda (Ruta graveolens), eucalipto (Eucalyptus spp.) e hortelã (Mentha piperita) e de plantas sobre o ácaro $V$. destructor, em colônias de A. mellifera africanizadas.

\section{Material e Métodos}

O experimento foi realizado no Município de Santana do Livramento, na região da Campanha, no RS, em junho e julho de 2005. O apiário está localizado a $210 \mathrm{~m}$ de altitude $\left(30^{\circ} 53^{\prime} 33^{\prime \prime} \mathrm{S}\right.$ e $\left.58^{\circ} 31^{\prime} 16^{\prime \prime} \mathrm{W}\right)$. As temperaturas no local, durante o experimento, variaram de $-1,0$ a $30^{\circ} \mathrm{C}$, com média de temperaturas mínimas de $7,2^{\circ} \mathrm{C}$ e máximas de $21,7^{\circ} \mathrm{C}$.

$\mathrm{O}$ apiário selecionado compunha-se de 50 enxames de abelhas A. mellifera (africanizadas), alojadas em colmeias de padrão Langstroth. Destas, foram selecionadas 30 colmeias, com sintomas de infestação pelo ácaro parasita $V$. destructor, como presença de favos com opérculos perfurados ou totalmente abertos, que continham pupas mortas com asas deformadas e abdômens reduzidos.

Utilizou-se o delineamento experimental inteiramente casualizado, com seis tratamentos e cinco repetições, no total de 30 colônias de abelhas africanizadas. Os tratamentos foram: T1, óleo essencial de arruda (Ruta graveolens); T2, ácido oxálico; T3, timol; T4, óleo essencial de eucalipto (Eucalyptus spp.); T5, óleo essencial de hortelã (Mentha piperita); e controle, sem aplicação de produto. Nas colmeias selecionadas, não foi aplicado previamente qualquer tipo de produto no controle do ácaro. Os produtos testados foram adquiridos em estabelecimentos comerciais, especializados na venda de produtos naturais.

As colônias do $\mathrm{T} 1$ receberam $10 \mathrm{~mL}$ de essência de arruda, aplicados em duas placas de vermiculita (esponja floral, 2x8x8 cm). Para o tratamento T2, foram diluídos $100 \mathrm{~g}$ de ácido oxálico em $1 \mathrm{~L}$ de água, misturado com $1 \mathrm{~kg}$ de açúcar. Obteve-se uma solução com $4,7 \%$ de ácido oxálico e de $47,6 \%$ de sacarose $\left(\mathrm{p} \mathrm{v}^{-1}\right)$. As aplicações foram realizadas por meio de um pulverizador costal com um calibrador/ dosificador calculado para $20 \mathrm{~mL}$ da solução por colônia, no total de três aplicações em 16 dias. Quanto aos tratamentos T3, T4 e T5, foram utilizadas duas placas de vermiculita (esponja floral), que receberam as seguintes substâncias: T3, $10 \mathrm{~g}$ de timol em pó, diluídos em $10 \mathrm{~mL}$ de álcool; T4, $10 \mathrm{~mL}$ de essência de eucalipto; e T5, 10 mL de essência de hortelã. Nesses, as duas placas de vermiculita, após serem imersas nos respectivos produtos, foram distribuídas na parte superior dos favos das colônias. As aplicações foram realizadas no período da manhã, às $8 \mathrm{~h}$ e, a cada oito 
dias, nova quantidade de cada produto foi aplicada às colônias, no total de três aplicações.

Dois dias antes da aplicação dos produtos, o nível de infestação de varroa em abelhas adultas foi determinado por meio da remoção de aproximadamente 100 abelhas adultas, aderidas a um quadro no centro das colmeias, para um becker de $200 \mathrm{~mL}$ com mistura à proporção de 1:3 de álcool:água. Em seguida, o frasco foi agitado, e o seu conteúdo foi transferido para um vasilhame branco para a contagem de abelhas.

Para determinar a taxa de infestação de varroa nas crias de abelhas, foi retirado um favo com pupa operculada do centro de cada ninho. Com auxílio de uma pinça, cerca de 100 células foram abertas para a retirada das pupas, tendo-se contado o número de ácaros presentes em cada célula. A taxa de infestação - número de ácaros por célula - foi determinada por meio da divisão do número de ácaros pelo número de pupas.

A taxa de mortalidade das crias de abelhas, antes do início do período experimental, foi determinada pela quantidade de crias que não conseguiram completar a metamorfose, ou seja, que não passaram de larva de quinto instar para pupa. Para essa avaliação, uma semana antes da aplicação dos tratamentos, foi retirado um favo com cria desoperculada do centro de cada colônia; sobre ele, foi colocado um pedaço

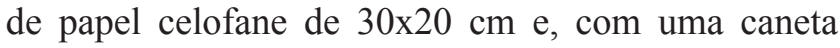
hidrocor, foram mapeadas, no papel, aproximadamente 100 células que continham crias com cinco dias de vida. Em cada um dos mapeamentos, foram identificados o favo, a colônia e a data. Depois de 10 dias, com a ajuda dos mapeamentos realizados anteriormente, foi feita a contagem do número de crias que haviam sido removidas ou das que estavam mortas (Castagnino et al., 2011).

A taxa de mortalidade das crias, após o período experimental, foi semelhanteà do início do experimento, tomando-se como parâmetro a quantidade de crias que não conseguiram completar a sua metamorfose e não emergiram do favo como abelha adulta.

Os dados foram submetidos à análise de variância, e as médias foram comparadas pelo teste de Kruskall-Wallis, a 5\% de probabilidade (SAS Institute, 2001).

\section{Resultados e Discussão}

$\mathrm{Na}$ comparação dos períodos anterior e posterior à aplicação dos produtos, verificou-se que os tratamentos com ácido oxálico e timol promoveram redução significativa do número de ácaros em crias de abelhas operárias, de 89 e $67,1 \%$, respectivamente (Tabela 1). Os tratamentos com arruda, eucalipto e hortelã causaram redução do número de ácaros de 40, 30 e $66,6 \%$, respectivamente, embora não tenham diferido significativamente entre si e em relação ao controle. No grupo controle, a taxa de redução da mortalidade do ácaro em relação ao período anterior à implantação do experimento foi de $19,6 \%$. A taxa de infestação pelo ácaro, antes da aplicação dos produtos, foi semelhante em todos os tratamentos.

A taxa de infestação média de varroas nas crias de abelhas operárias, nos seis tratamentos, antes da aplicação dos produtos, foi de 14,8\%. Este índice elevado de infestação nas crias pode estar relacionado ao período do ano. $\mathrm{Na}$ época em que foi realizado o experimento, em razão da baixa temperatura e da falta de alimento, as rainhas reduziram a postura, o que acarretou a diminuição de crias na colônia. Assim, essas poucas crias tornaram-se as únicas disponíveis para as fêmeas de $V$. destructor parasitar, o que aumentou a frequência de crias que continham o ectoparasita e, consequentemente, elevou a taxa de infestação nas crias. Dados semelhantes foram encontrados por Gregorc \& Planinc (2002) e Gregorc \& Poklukar (2003), que observaram diferenças na eficácia do tratamento em épocas do ano diferentes. Os autores constataram que a aplicação de acaricidas nos períodos de cria operculada não seria recomendável, uma vez que os ácaros estariam protegidos pelo opérculo.

Houve redução significativa da taxa de infestação do ácaro em abelhas adultas nos tratamentos com arruda, ácido oxálico e timol (Tabela 2), de 68,1, 87,4 e 70\%, respectivamente. Nos tratamentos controle, eucalipto e hortelã, a redução em relação ao período antes da

Tabela 1. Infestação (\%) de Varroa destructor em cria de abelhas Apis mellifera africanizadas, antes e depois dos tratamentos com arruda, ácido oxálico, timol, eucalipto e hortelã $\tilde{a}^{(1)}$.

\begin{tabular}{lcc}
\hline Tratamento & Antes & Depois \\
\hline Controle & $11,96 \pm 8,9 \mathrm{aA}$ & $9,61 \pm 3,3 \mathrm{aA}$ \\
Arruda & $9,03 \pm 5,6 \mathrm{aA}$ & $5,43 \pm 4,4 \mathrm{aA}$ \\
Ácido oxálico & $18,41 \pm 8,2 \mathrm{aA}$ & $2,04 \pm 3,1 \mathrm{bB}$ \\
Timol & $17,50 \pm 8,2 \mathrm{aA}$ & $5,75 \pm 1,7 \mathrm{bB}$ \\
Eucalipto & $10,03 \pm 6,2 \mathrm{aA}$ & $7,03 \pm 4,5 \mathrm{aA}$ \\
Hortelã & $21,83 \pm 14,3 \mathrm{aA}$ & $7,29 \pm 6,3 \mathrm{aA}$ \\
\hline
\end{tabular}

${ }^{(1)}$ Média \pm desvio-padrão seguida de letras iguais, minúsculas nas linhas e maiúsculas nas colunas, não diferem entre si, a 5\% de probabilidade. 
aplicação dos tratamentos foi de $6,8,37,1$ e $34,8 \%$, respectivamente.

A taxa de infestação pelo ácaro em abelhas adultas, antes da aplicação dos produtos, foi semelhante em todos os tratamentos (Tabela 2). Após a aplicação, verificou-se que o tratamento com ácido oxálico causou redução significativa da taxa de infestação, em comparação ao controle. Os demais tratamentos reduziram a taxa de infestação em abelhas adultas, quando comparados ao controle, embora essa redução não tenha sido significativa.

Durante o experimento, constatou-se que os óleos essenciais testados não tiveram efeito significativo na mortalidade das abelhas, em comparação ao controle. Tal fato mostra que esses produtos não apresentaram toxicidade e podem ser usados nas colmeias.

A significância do tratamento com óleo essencial de arruda, quanto à mortalidade de varroas, está de acordo com os resultados encontrados por Flores et al. (2000), em laboratório. Em 24 horas, os autores obtiveram $94,8 \%$ de mortalidade de $V$. destructor e constataram a eficiência desse óleo como acaricida. Potenza et al. (2006), ao realizar experimento de controle da população do ácaro-rajado (Tetranychus urticae) com extratos aquosos da arruda também obtiveram resultados significativos.

Comparando-se os períodos anterior e posterior à aplicação dos produtos, pôde-se constatar que todos os tratamentos, com exceção do controle, proporcionaram redução significativa da mortalidade de crias de abelhas. As magnitudes de redução foram de: $83,3 \%$, óleo essencial de arruda; $92,1 \%$, ácido oxálico; $81,7 \%$, timol; $86,4 \%$ eucalipto; e $81,3 \%$, hortelã. Segundo Carvalho \& Fonseca (2006), os óleos essenciais são formados por compostos naturais, como os monoterpenoides e arilpropanoides, que servem a várias funções nas

Tabela 2. Infestação (\%) de Varroa destructor em abelhas adultas, antes e depois dos tratamentos com arruda, ácido oxálico, timol, eucalipto e hortelã ${ }^{(1)}$.

\begin{tabular}{lrc}
\hline Tratamento & \multicolumn{1}{c}{ Antes } & Depois \\
\hline Controle & $6,92 \pm 3,14 \mathrm{aA}$ & $6,45 \pm 1,54 \mathrm{aA}$ \\
Arruda & $10,34 \pm 4,40 \mathrm{aA}$ & $3,29 \pm 3,46 \mathrm{bA}$ \\
Ácido oxálico & $7,09 \pm 4,37 \mathrm{aA}$ & $0,89 \pm 1,73 \mathrm{bB}$ \\
Timol & $9,84 \pm 3,49 \mathrm{aA}$ & $2,96 \pm 4,17 \mathrm{bA}$ \\
Eucalipto & $7,64 \pm 4,34 \mathrm{aA}$ & $4,80 \pm 2,18 \mathrm{aA}$ \\
Hortelã & $6,72 \pm 3,76 \mathrm{aA}$ & $4,38 \pm 2,39 \mathrm{aA}$ \\
\hline
\end{tabular}

${ }^{(1)}$ Média \pm desvio-padrão seguida de letras iguais, minúsculas nas linhas e maiúsculas nas colunas, não diferem entre si, a $5 \%$ de probabilidade. plantas, entre as quais, a de defendê-las contra ataques de insetos, ácaros e patógenos, o que explicaria tal ação. No tratamento controle, verificou-se redução não significativa de mortalidade de crias de $44,3 \%$.

Ao se comparar os tratamentos com o controle, constatou-se que a taxa de mortalidade de crias nos tratamentos, apesar de menor, não foi significativamente diferente da observada no controle após a aplicação dos produtos (Tabela 3 ).

Ruiz et al. (1998), ao testar in vitro o efeito dos óleos essenciais de arruda, urtiga (Urtiga dioica) e menta sobre $V$. destructor, em $A$. mellifera europeias, constataram que a arruda e a menta apresentaram grande eficácia na mortalidade do ácaro. Segundo Isman (2006), os metabólicos secundários de algumas plantas são eficientes no controle de ácaros.

Entre os produtos testados, o ácido oxálico foi o que apresentou melhor eficácia no controle da varroa. Esse resultado também refletiu-se na redução da taxa de infestação e mortalidade nas crias de abelhas, de 89 e $92,1 \%$, respectivamente, o que mostra que esta ocorreu em consequência da redução da população de ácaros nas colmeias. Em experimentos similares, Rademacher \& Harz (2006), ao aplicar solução de 3\% de ácido oxálico em água e açúcar, obtiveram mais de $90 \%$ de mortalidade de varroas. Os resultados obtidos no presente trabalho indicam que a aplicação do ácido oxálico é uma alternativa eficiente no controle do ácaro, quando aplicado em colônias no período de pouca ou nenhuma cria. Estes dados corroboram os de Gregorc \& Planinc (2001), que obtiveram média de 99,4\% de mortalidade dos ácaros totais na colônia. Segundo esses autores, o efeito do produto tornou-se limitado, quando as crias estavam operculadas, uma vez que as fêmeas do ácaro permaneceram 12 dias dentro das células com as crias, até o seu desenvolvimento

Tabela 3. Taxa de mortalidade de cria (\%) de abelhas Apis mellifera, antes e depois dos tratamentos com arruda, ácido oxálico, timol, eucalipto e hortelã ${ }^{(1)}$.

\begin{tabular}{llc}
\hline Tratamento & \multicolumn{1}{c}{ Antes } & Depois \\
\hline Controle & $35,21 \pm 16,73 \mathrm{aA}$ & $19,61 \pm 15,18 \mathrm{aA}$ \\
Arruda & $33,17 \pm 10,09 \mathrm{aA}$ & $5,53 \pm 4,57 \mathrm{bA}$ \\
Ácido oxálico & $32,32 \pm 6,15 \mathrm{aA}$ & $2,55 \pm 3,33 \mathrm{bA}$ \\
Timol & $31,43 \pm 3,35 \mathrm{aA}$ & $5,75 \pm 1,73 \mathrm{bA}$ \\
Eucalipto & $51,67 \pm 36,02 \mathrm{aA}$ & $7,03 \pm 0,77 \mathrm{bA}$ \\
Hortelã & $39,00 \pm 23,00 \mathrm{aA}$ & $7,29 \pm 6,32 \mathrm{bA}$ \\
\hline
\end{tabular}

${ }^{(1)}$ Média \pm desvio-padrão seguida de letras iguais, minúsculas nas linhas e maiúsculas nas colunas não diferem entre si, a $5 \%$ de probabilidade. 
completo. Nessa fase de desenvolvimento da abelha, o opérculo protegeria a varroa e não permitiria o contato direto com os produtos aplicados para o seu controle. Assim, as varroas que estivessem parasitando as crias de abelhas operculadas poderiam ficar protegidas, sem ter contato com o ácido oxálico. Entretanto, no presente trabalho, como foram realizadas aplicações diretas do produto nos favos, a cada cinco dias, no total de 16 dias, pôde-se inferir que grande parte das varroas entrou em contato com o produto, mesmo aquelas que estavam protegidas pelo opérculo na aplicação anterior. Constatou-se, então, que o uso de três aplicações, por mais de 12 dias, é uma importante prática de manejo para aumentar a eficácia dos produtos acaricidas.

Outros fatores também devem ser considerados, para que a aplicação do ácido oxálico seja mais eficiente. A média das temperaturas mínimas, durante a fase experimental, foi de $7,2^{\circ} \mathrm{C}$. Essas baixas temperaturas ocasionaram o agrupamento de grande quantidade de abelhas operárias ao redor da cria, para protegê-la das baixas temperaturas. Como o produto foi aplicado às $8 \mathrm{~h}$, possivelmente ainda havia grande quantidade de abelhas presentes no interior da colmeia, o que teria favorecido o contato direto destas com o produto.

O estágio fisiológico das abelhas também é outro fator importante, pois, a pequena quantidade de crias operculadas nessa época do ano fez com que a maior parte das fêmeas do $V$. destructor estivesse na fase forética, quando ainda estão aderidas ao corpo das abelhas adultas. Essas condições permitiram que as fêmeas de varroa estivessem mais expostas e vulneráveis à ação tópica do produto. Estes resultados corroboram os de Gregorc \& Planinc (2002) e Gregorc \& Poklukar (2003), que enfatizam a importância da época correta do ano para aplicar os acaricidas, com a finalidade de se obter maior eficácia do produto.

O timol também mostrou-se eficaz na redução da taxa de infestação em abelhas adultas. $\mathrm{O}$ controle efetivo da população de varroa, em abelhas adultas, deve ter como consequência a redução da taxa de mortalidade das crias de abelhas pelo ectoparasita. Pesquisas têm mostrado que, entre os produtos alternativos usados no controle de $V$. destructor, o timol vem se destacando pela eficácia. May-Itzá et al. (2007) verificaram que uma segunda aplicação de timol, em um intervalo de 15 dias, eliminou 95\% de varroas em colônias de abelhas. Segundo os autores, esse produto pode ser usado como método alternativo para o controle desse parasita.

A mortalidade do ectoparasita pode ser explicada pela ação tóxica direta do timol nas varroas aderidas ao corpo das abelhas adultas. Também é possível que o timol tenha mascarado a ação dos ferormônios, liberados pelas crias abertas antes de serem operculadas (Allam et al., 2003). Tal fato pode ter dificultado a localização das crias pelo ectoparasita, tornando-o mais exposto ao ataque das abelhas adultas por meio do comportamento denominado de "grooming". Este comportamento está associado à capacidade das abelhas operárias de atacarem as varroas, retirando-as do seu próprio corpo (alogrooming) ou de uma abelha vizinha. Em estudo de coleta da varroa em colmeias de abelhas africanizadas, Côrrea-Marques et al. (2000) observaram que várias partes do corpo dos ácaros estavam mutiladas, o que indica comportamento de "grooming" das abelhas adultas.

Além disso, a aplicação do timol pode ter provocado irritação no espiráculos das abelhas e aumentado o comportamento de "grooming", com consequente redução na taxa de infestação das abelhas adultas. Stanghellini \& Raybold (2004) verificaram aumento nas taxas de remoção de ácaros pelas abelhas, motivado pela aplicação de produtos, dos quais o timol era o principal componente.

No presente trabalho, entre os óleos essenciais, o de eucalipto apresentou o melhor resultado na redução de mortalidade de cria de abelhas. Segundo Macedo et al. (2009), esse resultado poderia estar relacionado às substâncias secundárias eucaliptol e citronela, que têm ação acaricida e inseticida e são dois dos principais componentes do óleo de algumas espécies de Eucalyptus sp. A ação acaricida do óleo essencial de hortelã $(M$. piperita) pode estar relacionada à presença do mentol, pois este é o principal componente volátil identificado, que varia entre 33 e $60 \%$.

Segundo Kraus et al. (1994), como o olfato é o principal fator de reconhecimento de abelhas adultas pelas varroas, é possível que, a exemplo do timol, os demais óleos essenciais utilizados no experimento possam ter causado alterações na orientação olfatória das varroas.

Trabalhos realizados por Spivak \& Downey (1998) e Gramacho et al. (1999) mostram que a pupa de abelha morta, doente ou infectada pelo $V$. destructor, é um forte estímulo para que as abelhas façam a sua remoção da 
colônia, o que diminui a taxa de infestação na colmeia. Dessa forma, a diminuição na mortalidade de crias observada no tratamento controle, na comparação dos períodos anterior e posterior à aplicação dos produtos, pode estar relacionada ao comportamento higiênico das colmeias, que é a habilidade genética das abelhas de detectar, desopercular e remover crias mortas, doentes ou com ácaro dentro de suas células de cria para fora da colônia. Este comportamento é uma defesa natural das abelhas, principalmente contra doenças de crias.

Existe também a possibilidade de que a mortalidade de abelhas adultas, no local do experimento, não seja exclusivamente de ação direta dos ácaros e, sim, de outros patógenos que tenham como vetor o $V$. destructor, entre eles a presença de vírus. Segundo Colin et al. (2001), o ácaro pode servir como vetor, ao injetar partículas de vírus na hemolinfa da abelha, o que pode ocasionar várias doenças. Recentemente, após relatos de perdas de colmeias no Uruguai por razões desconhecidas, Antúnez et al. (2006) constataram a presença de vírus (CBPV), (ABPV), (BQCV), (SBV) e (DWV) em amostras de abelhas deste país. Os autores relacionaram as perdas de colônias à presença do ácaro $V$. destructor como vetor dos vírus, o que configura o primeiro relato da presença do patógeno na América do Sul.

No Brasil, tal observação também foi relatada por Teixeira et al. (2008) que, ao pesquisar a mortalidade de abelhas associada à alta taxa de varroa em colmeias, na região de São Paulo, encontraram infestação de $10,68 \%$ do ácaro $V$. destructor em abelhas adultas, e $9 \%$ nas células de crias - níveis bem acima dos observados nos anos anteriores. Nas colmeias estudadas, os autores encontraram a presença dos vírus (ABPV), (BQCV) e (DWV), e também relacionaram a mortalidade das colônias à presença do ácaro e sua ação como vetor desses vírus. Do total das amostras analisadas, 96\% delas apresentavam pelo menos um tipo de vírus.

Castagnino et al. (2009) sugerem, como formas de atenuar a dispersão de doenças, a revisão periódica nas áreas de cria, o reconhecimento de sintomas das doenças, cuidados na prática da apicultura migratória para regiões onde houve constatação de doença e seleção genética de colmeias mais resistentes, para prevenir novas enfermidades.

\section{Conclusões}

1. Os óleos essenciais - arruda, eucalipto, hortelã, timol - e o ácido oxálico são eficientes na redução da mortalidade de crias de abelhas Apis mellifera africanizadas parasitadas pelo ácaro Varroa destructor.

2. O ácido oxálico e o timol promovem a redução significativa da infestação de varroas nas crias de abelhas; e o ácido oxálico é eficiente na redução da infestação do ácaro em abelhas adultas e nas colmeias de abelhas $A$. mellifera africanizadas.

\section{Referências}

ALLAM, S.F.M.; HASSAN, M.F.; RISK, M.A.; ZAKI, A.U. Utilization of essential oils and chemical substances alone or in combination against Varroa mite (Varroa destructor), a parasite of honeybees. IOBC/WPRS Bulletin, v.26, p.273-278, 2003.

ANDERSON, D.L.; TRUEMAN, J.W.H. Varroa jacobsoni (Acari: Varroidae) is more than one species. Experimental and Applied Acarology, v.24, p.165-189, 2000.

ANTÚNEZ, K.; D’ALESSANDRO, B.; CORBELLA, E.; RAMALLO, G.; ZUNINO, P. Honeybee viruses in Uruguay. Journal of Invertebrate Pathology, v.93, p.67-70, 2006.

BAGGIO, A.; ARCULEO, P.; NANETTI, A.; MARINELLI, E.; MUTINELLI, F. Field trials with different thymol-based products for the control of varrosis. American Bee Journal, v.144, p.395-400, 2004.

BOGDANOV, S. Contaminants of bee products. Apidologie, v.37, p.1-18, 2006.

CARNEIRO, F.E.; TORRES, R.R.; STRAPAZZON, R.; RAMÍREZ, S.A.; GUERRA JUNIOR, J.C.V.; KOLING, D.F.; MORETO, G. Changes in the reproductive ability of the mite Varroa destructor (Anderson e Trueman) in Africanized honey bees (Apis mellifera L.) (Hymenoptera: Apidae) colonies in Southern Brazil. Neotropical Entomology, v.36, p.949-952, 2007.

CARVALHO, C.C.R. de; FONSECA, M.M.R. Carvone: why and how should one bother to produce this terpene. Food Chemistry, v.95, p.413-422, 2006.

CASTAGNINO, G.L.; ORSI, R. de O.; FUNARI, S.R. da C. Éster de sacarose no controle do Varroa destructor em abelhas africanizadas. Acta Scientiarum. Animal Sciences, v.31, p.287-293, 2009.

CASTAGNINO, G.L.B.; MESSAGE, D.; MARCO JÚNIOR, P. de. Fornecimento de substituto de pólen na redução da mortalidade de Apis mellifera L. causada pela cria ensacada brasileira. Ciência Rural, v.41, p.1838-1843, 2011.

COLIN, M.; TCHAMITCHIAN, M.; BONMATIN, J.-M.; DI PASQUALE, S. Presence of chitinase in adult Varroa destructor, an ectoparasitic mite of Apis mellifera. Experimental and Applied Acarology, v.25, p.947-955, 2001. 
CORRÊA-MARQUES, M.H.; CAVICCHIO, M.R.; DE JONG, D. Classification and quantification of damaged Varroa jacobsoni found in the debris of honey bee colonies as criteria for selection? American Bee Journal, v.140, p.820-824, 2000.

DAMIANI, N.; GENDE, L.B.; BAILAC, P.; MARCANGELI, J.A.; EGUARAS, M.J. Acaricidal and insecticidal activity of essential oils on Varroa destructor (Acari: Varroidae) and Apis mellifera (Hymenoptera: Apidae). Parasitology Research, v.106, p.145-152, 2009.

DUAY, P.; DE JONG, D.; ENGELS, W. Weight loss in drone pupae (Apis mellifera) multiply infested by Varroa destructor mites. Apidologie, v.34, p.61-65, 2003.

FLORES, J.M.; RUIZ, J.A.; CUNHA, S.R. Situación actual y perspectivas de los tratamientos en el control de Varroa jacobsoni Oud. en Andalucía. Vida Apícola, v.104, p.27-31, 2000.

GRAMACHO, K.P.; GONÇALVES, L.S.; ROSENKRANZ, P.; DE JONG D. Influence of body fluid from pin-killed honey bee pupae on hygienic behavior. Apidologie, v.30, p.367-374, 1999.

GREGORC, A.; PLANINC, I. Acaricidal effect of oxalic acid in honeybee (Apis mellifera) colonies. Apidologie, v.32, p.333-340, 2001.

GREGORC, A.; PLANINC, I. The control of Varroa destructor using oxalic acid. The Veterinary Journal, v.163, p.306-310, 2002.

GREGORC, A.; POKLUKAR, J. Rotenone and oxalic acid as alternative acaricidal treatments for Varroa destructor in honeybee colonies. Veterinary Parasitology, v.111, p.351-360, 2003.

ISMAN, M.B. Botanicals insecticides, deterrents, and repellents in modern agriculture and increasingly regulated world. Annual Revision Entomology, v.51, p.45-66, 2006.

KRAUS, B.; KOENIGER, N.; FUCHS, S. Screening of substances for their effect on Varroa jacobsoni: attractiveness, repellency, toxicity and masking effects of ethereal oils. Journal of Apicultural Research, v.33, p.34-43, 1994.

LODESANI, M. Control strategies against Varroa mites. Parasitologia, v.46, p.277-279, 2004.

MACEDO, I.T.F.; BEVILAQUA, C.M.L.; OLIVEIRA, L.M.B. de; CAMURÇA-VASCONCELOS, A.L.F.; VIEIRA , L. da S.; OLIVEIRA, F.R.; QUEIROZ-JUNIOR, E.M; PORTELA, B.G.; BARROS, R.S.; CHAGAS, A.C.S. Atividade ovicida e larvicida in vitro do óleo essencial de Eucalyptus globulus sobre Haemonchus contortus. Revista Brasileira de Parasitologia Veterinária, v.18, p.62-66, 2009.

MAY-ITZÁ, W. de J.; MEDINA MEDINA, L.A.; MARRUFO OLIVARES, J.C. Eficacia de un gel a base de timol en el control del ácaro Varroa destructor que infesta colonias de abejas Apis mellifera, bajo condiciones tropicales en Yucatán, México. Veterinaria México, v.38, p.1-8, 2007.

POTENZA, M.R.; GOMES, R.C.O.; JOCYS, T.; TAKEMATSU, A.P.; RAMOS, A.C.O. Avaliação de produtos naturais para o controle do ácaro rajado Tetranychus urticae (Koch, 1836) (Acari: Tetranychidae) em casa de vegetação. Arquivos do Instituto Biológico, v.73, p.455-459, 2006.

RADEMACHER, E.; HARZ, M. Oxalic acid for the control of varrosis in honey bee colonies - a review. Apidologie, v.37, p.98-120, 2006.

RUIZ, J.A.; FLORES, J.M.; RUZ, J.M.; PUERTA, F.; CAMPANO, F. Eficacia de plantas medicinales contra Varroa jacobsoni Oud. en laboratorio: una alternativa para el mundo rural del tercer milenio. Vida Apícola, v.96. p.513-519, 1998.

SAS INSTITUTE. SAS/STAT user's guide statistics. Version 8. Cary: SAS Institute, 2001.

SPIVAK, M.; DOWNEY, D.L. Field assays for hygienic behavior in honey bees (Hymenoptera: Apidae). Journal of Economic Entomology, v.91, p.64-70, 1998.

STANGHELLINI, M.S.; RAYBOLD, P. Evaluation of selected biopesticides for the late fall control of varroa mites in a northern temperate climate. ABJ, v.144, 2004. Available at: $<$ http://www. mitegone.com/forms/Dr\%20M\%20Stanghellini\%20Report\%20 Edited.pdf>. Accessed on: 20 Nov. 2010.

TEIXEIRA, E.W.; CHEN, Y.; MESSAGE, D.; PETTIS, J.; EVANS, J.D. Virus infections in Brazilian honey bees. Journal of Invertebrate Pathology, v.99, p.117-119, 2008.

TENTCHEVA, D.; GAUTHIER, L.; BAGNY, L.; FIEVET, J.; DAINAT, B.; COUSSERANS, F.; COLIN, M.E.; BERGOIN, M. Comparative analysis of deformed wing virus (DWV) RNA in Apis mellifera and Varroa destructor. Apidologie, v.37, p.41-50, 2006.

TOOMEMAA, K.; MARTIN, A.-J.; WILLIAMS, I.H. The effect of different concentrations of oxalic acid in aqueous and sucrose solution on Varroa mites and honey bees. Apidologie, v.41, p.643-653, 2010.

Recebido em 26 de novembro de 2010 e aprovado em 3 de maio de 2012

Pesq. agropec. bras., Brasília, v.47, n.6, p.738-744, jun. 2012 